\title{
PRIMARY LUMBAR HERNIA- A CASE REPORT
}

\author{
Himadri Sekhar Kar1, Sartaj Sohail2, Mohammad Ahmad ${ }^{3}$
}

${ }^{1}$ Assistant Professor, Department of General Surgery, MMC and H, Midnapore, West Bengal.

2 Postgraduate Trainee, Department of General Surgery, MMC and H, Midnapore, West Bengal.

${ }^{3}$ Postgraduate Trainee, Department of General Surgery, MMC and H, Midnapore, West Bengal.

HOW TO CITE THIS ARTICLE: Kar HS, Sohail S, Ahmad M. Primary lumbar hernia- a case report. J. Evolution Med. Dent. Sci. 2018;7(02):256-258, DOI: $10.14260 /$ jemds/2018/57

\section{PRESENTATION OF CASE}

The patient is a 47-year-old, average built male patient presenting in the outpatient department with complaints of left-sided back swelling with vague pain for last 6 months. On further evaluation, the patient revealed that the swelling is gradually increasing in size and the swelling further increases on sitting and coughing. There was no history of trauma, surgery or infection at that site. Bowel and bladder was within normal limit with no history of obstructive uropathy or constipation. No history of any addiction. On examination, a swelling was noted in left superior lumbar region. It was $5 \times 5 \mathrm{~cm}$ in size, globular in shape, non-tender and nonpulsatile, partially reducible in nature. Auscultation was nonspecific. On review of his labs, his routine investigation was within normal limit. High resolution ultrasonography of swelling showed an intramuscular defect in the left superior lumbar region with herniation of omentum through the defect. Hence, a diagnosis of primary lumbar hernia was established. The patient was posted for operation after all required investigations and defect was closed by mesh hernioplasty by polypropylene mesh. Postoperative period was uneventful.

\section{DIFFERENTIAL DIAGNOSES}

Based on History and Clinical Examination, the various Differential Diagnoses Includes

- Lumbar hernia.

- Lipoma.

- Fibroma.

- Chronic Abscess.

- Chronic Haematoma (post trauma).

\section{CLINICAL DIAGNOSIS}

Clinically, the most obvious diagnosis in this case appears to be that of a left-sided primary lumbar hernia.

\section{PATHOLOGICAL DISCUSSION}

Lumbar hernias are rare among all other hernias. Hafner et al stated that general surgeons will get only one opportunity to repair a lumbar hernia during their lifetime. ${ }^{1}$ Lumbar hernia was first suggested by P. Barbette in 1672 and R. J. C. Garangeot published a case for the first time in 1731. Since then, only about 310 cases have been reported. ${ }^{2}$

'Financial or Other Competing Interest': None.

Submission 22-11-2017, Peer Review 17-12-2017,

Acceptance 23-12-2017, Published 08-01-2018.

Corresponding Author:

Sartaj Sohail,

Khan Manzil, Near Irshad Ali Clinic,

Panpara, PO-Midnapore, PS-Kotwali,

Midnapore Dist-Paschim Mednipur-721101,

West Bengal.

E-mail: sartaj.shl@gmail.com

DOI: $10.14260 /$ jemds/2018/57

\section{(c) $($ ) $\$$}

The lumbar region is bordered superiorly by the 12 th rib inferiorly by the iliac crest, medially by the erector spinae muscles and laterally by the external oblique muscle. Lumbar hernias occur through two potential weak spaces, which are superior and inferior lumbar triangles. The superior lumbar space of Grynfeltt and Lesshaft is the larger one. It is an inverted triangle the base of which is formed by the 12th rib and the lower edge of serratus posterior inferior muscle, anteriorly bounded by the posterior border of internal oblique muscle, posteriorly bounded by the anterior border of sacrospinalis muscle. Floor is formed by the aponeurosis of transversus abdominis muscle and roof by the latissimus dorsi muscle. The inferior lumbar triangle of Petit is bounded anteriorly by the posterior border of external oblique muscle, posteriorly by the anterior border of latissimus dorsi muscle, base is formed by iliac crest, floor by the internal oblique muscle with contribution from transversus abdominis muscle and roof by skin and subcutaneous tissue. ${ }^{2}$ Lumbar hernias may be acquired or congenital (20\%) and typically the later manifest in childhood ${ }^{3-4}$ as an isolated phenomenon or in association with hereditary disorders such as syndrome of lumbar vertebral deficiency, meningocoele and neurofibromatosis. Acquired hernia may be primary $(50 \%$ $55 \%$ ), occurring in aged individuals, situations of increased intra-abdominal pressure or excessive weight loss and secondary (25\% - 30\%) caused by surgical procedure, blunt or open traumas. ${ }^{3-6}$ Other causes of acquired lumbar hernias include penetrating wounds $(75 \%-80 \%)$, pregnancy, tuberculosis, Pott's disease and extreme malnutrition. The most common site for the occurrence of lumbar hernias is in the superior lumbar triangle. ${ }^{7}$

\section{DISCUSSION OF MANAGEMENT}

The diagnosis is based on history and clinical examination of the patient. It usually presents as a tumour in the lumbar region with softened consistency, producing a sound at percussion, of reducible nature but susceptible to become irreducible and may be associated with vague pain. 4,8 Symptoms worsen under conditions of stress and typically cause discomfort and non-specific abdominal pain or back pain. Lumbar hernia is predominantly left sided and most frequently affects male individuals aged between $50-70$ years. ${ }^{4}$ As lumbar hernias may resemble with lipoma, tumour, chronic abscess, fibroma, or if a trauma have been involved a flank haematoma, advanced imaging becomes a necessity for the confirmation of diagnosis. ${ }^{9}$ CT scan/ MRI in patients with suspected hernias can confirm the diagnosis adding information on parietal defect size, hernial content and muscular trophism.10-16 Complications of lumbar hernias include incarceration, bowel obstruction, strangulation and volvulus. ${ }^{11,12}$ Surgery is the only treatment. ${ }^{17}$ Before the era of mesh plasty, Dowd repair ${ }^{18}$ was practiced. It involves closure of the defect, primarily using muscle flaps from 
gluteus major and medius muscle, latissimus dorsi muscle and tensor fascia lata. ${ }^{19}$ But the recurrence rate was high due to poor fascial strength and high tension of the repair. Later artificial mesh made of polypropylene was used to bridge the gap by Dowd-Ponka technique. ${ }^{20}$ In 1996, the first transabdominal laparoscopic approach was introduced by Burick and Parascandola. ${ }^{21} \mathrm{~A}$ similar technique was introduced by A Sharma et al.22 The balloon dissector was used in 1999 for total extraperitoneal approach, which was described by Woodward et al.23 A paper published in 2005 shows a prospective study of lumbar hernias repair- Classical versus Laparoscopic approach. It shows superiority of the laparoscopic group. ${ }^{24-26}$ More recently use of biosynthetic mesh has shown good result. ${ }^{27}$ Recurrence of lumbar hernia has not been reported yet. 4 In children surgical repair is performed at the age of $6-12$ months and in adults it is done immediately after diagnosis. 4,5

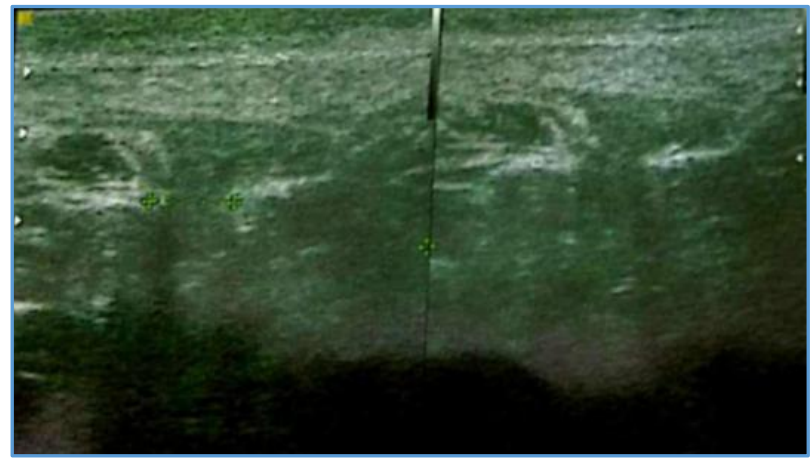

Figure 1. HR-USG of the Left Lumber Region shows the Hernial Defect

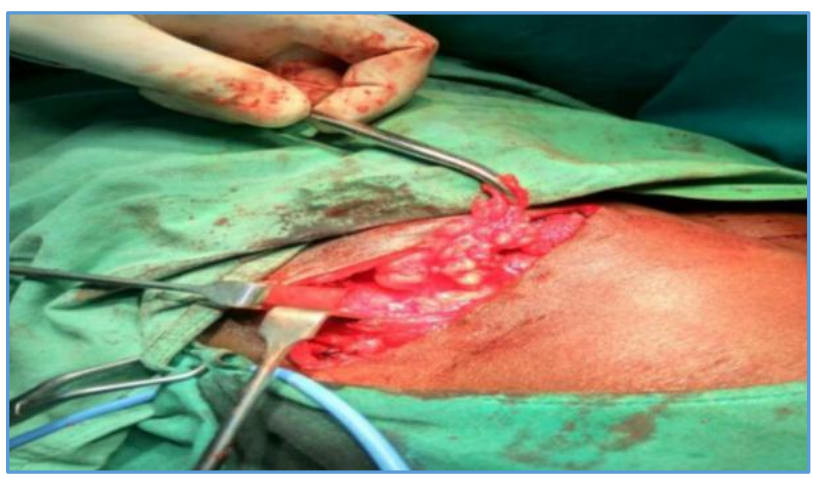

Figure 2. Hernial Defect with Omentum as the Content

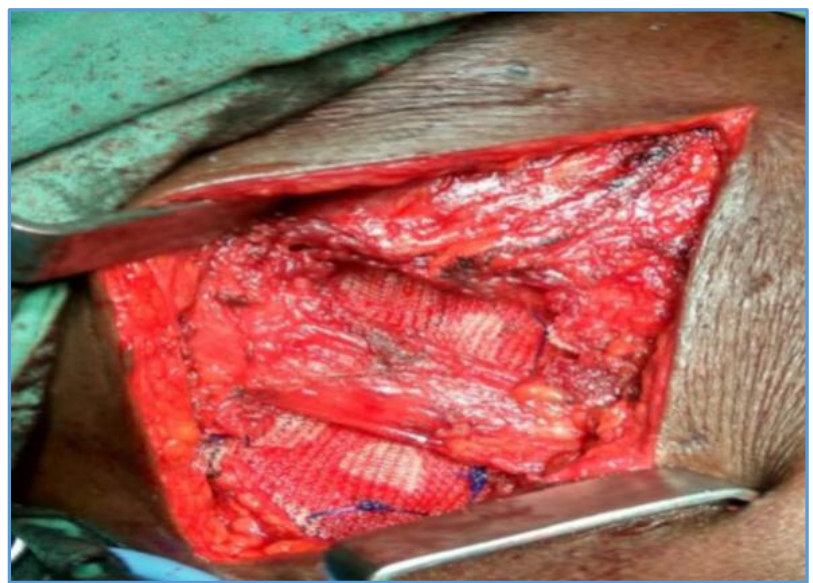

Figure 3. Intraoperative Images after Mesh Placement

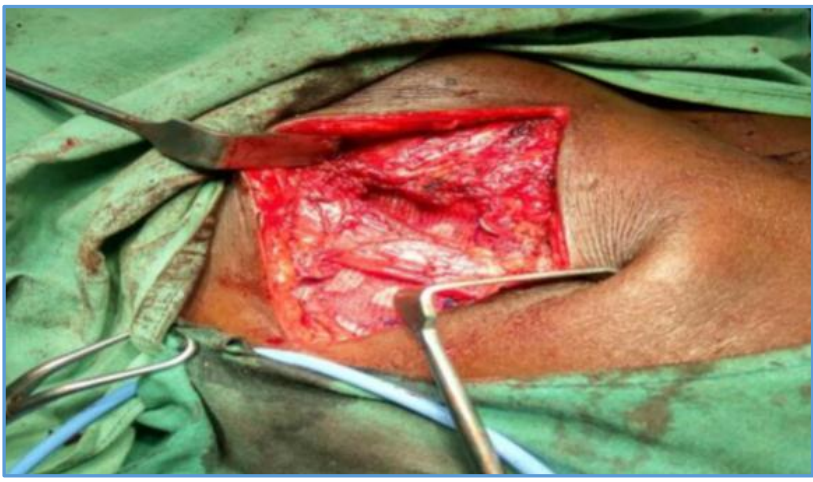

Figure 4. Intraoperative Images after Mesh Placement

\section{REFERENCES}

[1] Hafner CD, Wylie JH, Brush BE. Petit's lumbar hernia: repair with Marlex mesh. Arch Surg 1963;86(2):180-6.

[2] Moreno-Egea A, Baena EG, Calle MC, et al. Controversies in the current management of lumbar hernias. Arch Surg 2007;142(1):82-8.

[3] Prieto-Diaz-Chavez E, Medina-Chavez JL, Prieto-Diaz S. Grynfeltt's hernia. Hernia 2000;4(3):159-61.

[4] Guillem P, Czarnecki E, Duval G, et al. Lumbar Hernia: anatomical route assessed by computed tomography. Surg Radio Anat 2002;24(1):53-6.

[5] Karmani S, Ember T, Davenport R. Congenital lumbar hernias: a case report. J Pediatr Surg 2002;37(6):9212.

[6] Bauza LME, Fernandez BJF, Ramirez DA. Hernia bilateral de Grynfeltt. Informed de un caso. Rev Med IMSS 2003;41:339-43.

[7] Wakhlu A, Wakhlu AK. Congenital lumbar hernia. Pediatr Surg Int 2000;16(1-2):146-8.

[8] Skrekas G, Stafyla VK, Papalois VE. A Grynfeltt hernia: report of a case. Hernia 2005;9(2):188-91.

[9] Sarela AI, Mavanur AA, Bhaskar AA, et al. Post traumatic lumbar hernia. J Postgrad Med 1996;42(3):78-80.

[10] Hickey NA, Ryan MF, Hamilton PA, et al. Computed tomography of traumatic abdominal wall hernia and associated deceleration injuries. Can Assoc Radiol J 2002;53(3):153-9.

[11] Aguirre DA, Casola G, Sirlin C. Abdominal wall hernias: MDCT findings. AJR 2004;183(3):681-90.

[12] Baker ME, Weinerth JL, Andriani RT, et al. Lumbar hernia: diagnosis by CT. AJR Am J Roentgenol 1987;148(3):565-7.

[13] Killeen KL, Girard S, DeMeo JH, et al. Using CT to diagnose traumatic lumbar hernia. AJR Am J Roentgenol 2000;174(5):1413-5.

[14] Ng SSM, Ng NC, Liu SYW, et al. Radiology for the surgeon: soft-tissue case 58. Can J Surg 2006;49(2):129-30.

[15] Aguirre DA, Santosa AC, Casola G, et al. Abdominal wall hernias: imaging features, complications and diagnostic pitfalls at multi-detector row CT. Radiographics 2005;25(6):1501-20.

[16] Faro SH, Racette CD, Lally JF, et al. Traumatic lumbar hernia: CT diagnosis. AJR Am J Roentogenol 1990;154(4):757-9. 
[17] Armstrong 0, Hamel A, Grignon B, et al. Lumbar hernia: anatomical basis and clinical aspects. Surg Radiol Anat 2008;30(7):533-7.

[18] Dowd CN. Congenital lumbar hernia at the triangle of Petit. Annals of Surgery 1907;45(2):245-8.

[19] Swartz DWT. Lumbar hernia. In: Nyhus LM, Condon RE. eds. Hernia. 2nd edn. Philadelphia: Lippincott Williams \& Wilkins 1978:409-26.

[20] Skandalakis LJ, Skandalakis JE, Skandalakis PN. Surgical anatomy and technique. $3^{\text {rd }}$ edn. Springer 2008.

[21] Burick AJ, Parascandola SA. Laparoscopic repair of a traumatic lumbar hernia: a case report. J Laparoendosc Surg 1996;6(4):259-62.

[22] Sharma A, Panse R, Khullar R, et al. Laparoscopic transabdominal extraperitoneal repair of lumbar hernia. J Minimal Access Surgery 2005;1(2):70-3.
[23] Woodward AM, Flint LM, Ferrara JJ. Laparoscopic retroperitoneal repair of recurrent postoperative lumbar hernia. J Laparoendosc Adv Surg Tech A 1999;9(2):181-6.

[24] Moreno-Egea A, Torralba JA, Morales G, et al. Open vs. laparoscopic repair of secondary lumbar hernias: a prospective nonrandomized study. Surg Endosc 2005;19(2):184-7.

[25] Moreno Egea A, Guzman P, Girela E, et al. Laparoscopic hernioplasty in secondary lumbar hernias. J Laparoendosc Adv Surg Tech A 2006;16(6):572-6.

[26] Madan AK, Ternovist CA, Speck KE, et al. Laparoscopic lumbar hernia repair. Am Surg 2006;72(4):318-21.

[27] Beth-Ann S, Victoriya SC, Kelly J, et al. Repair of a traumatic lumbar hernia with biosynthetic mesh: a novel approach and review of the literature. J Curr Surg 2012;2(3):105-9. 